\title{
Research on the Application of Cultural Symbol Digitization in Movie Poster Design
}

\author{
Liu Chunyuan, Liu Li \\ Institute of Art \& Design Qingdao University of Technology Qingdao, Shandong Province, China
}

\begin{abstract}
With the vigorous development of the film industry, film posters, as the first impression of the film on the audience, break the language barrier and become an important medium for the output of cultural ideology. From the perspective of cultural symbols, this article explores the differences between the digitalization of Eastern and Western cultural symbols in the design of Chinese and foreign movie posters, and analyzes the digital symbols in the design of movie posters from a cultural perspective, providing a new thinking for the digital design of cultural symbols in movie posters.
\end{abstract}

\section{Semiotics Theory And Its Significance}

Semiotics theory believes that the environment people living in is a world of symbols, everything exists as the form of symbols. The symbolic view of Semiotics holds that all things take symbols as carriers and exchange information constantly, in other words, any expression of meaning needs to be adapted to the symbol as a medium to achieve transmission. As a kind of "meaning study", Semiotics studies the creation of Signified and explains the relationship between creative Signified. ${ }^{[1]}$ The meaning of Signified here can be understood as the implication of the symbol hidden behind various symbolic forms. Semiotician Ferdinand de Saussure proposed a binary model of symbols, which interpreted symbols by the two levels of Signifier and Signified.

As a dominant element, Signifier usually reflect the superficial phenomenon of things while Signified as a recessive element refers to the semiotic meaning which hidden behind Signifier. Saussure believes that the relationship between Signifier and Signified is the core of Semiotics. ${ }^{[2]}$ This relationship is expressed in various forms of expression through different rhetorical devices such as metaphor, synonymy, metonymy, and allegory.

Although there are many other subjects studying in significance in the scientific field such as Logic, Phenomenology, Cognition etc. However, Semiotics has the most general theoretical significance and practical character among these subjects which studying the significance of the general formal law from representation to communication to receiving. Culture, on the other, can be defined as a collection of all meanings of all society activities which means all cultural issues can be analyzed as the problem of the generation, dissemination and interpretation of significance. Thus, the core area of Semiotics concerned can be understood as human culture.

With the advent of the 21 st Century, there comes an unprecedented change in society that contemporary culture quickly rushes into a "Highly Symbolic Era", symbolic consumption has far exceeded physical consumption which indicates symbolic production has to exceed physical production.

Therefore, on the one hand, national industry needs symbolic activities to promote the formation of industrial culture and commodity culture, and if the country's production becomes a "raw product" that's lacking of brand and fashionable value, the whole industry will always be in rudimentary. On the other hand, culture itself is transforming into the cultural industry through systematic symbolic activities.

The culturalization of industry and the industrialization of culture, both achieved by symbolic activities have brought a great change in the economic structure of the world today. So the study of semiotics is urgent. Therefore, it is necessary to study Semiotics.

\section{Movies And Movie Posters}

Since the birth of film art more than a hundred years ago, as a continuous development system, it is always renewing the issues arising from artistic thinking from one era to another, while echoing the development of economy, politics, technology, and culture. Marshall McLuhan mentioned "The key factors that determine the social form of human history are not politics, economy and culture, but media." With the progress of the time, the level of technological development is changing with each passing day. As a new type of mass media, film has a natural advantage over traditional media due to its visualization of story plots, diversification of content themes, and authenticity of visual special effects, and this natural advantage earns more affinity and voice in the new generations,

At the same time, this affinity is also subtly affecting the audience's attitudes, cognition and even their 
formation of values. Therefore, the film has the attributes of cultural transmission and value output as an ideological art form. Compared with the more developed film industry system in the West, the Chinese film industry that still has to develop needs more excellent works such as "Wolf WarriorsII" and "Wandering Earth" to promote the Chinese spirit.

As a subsidiary cultural product of the movie, the role of movie posters is mainly to promote the movie. Before the movie is officially presented to the audience, it gives a certain horizon of expectation. ${ }^{[3]}$

In essence, as a visual symbol of the movie, it uses print media as a carrier to attract the audience while conveying the movies' theme, its visual elements include colors, graphics, text, etc.

Arnheim wrote in "Art and Visual Perception Art": "Vision is not a mechanical copy of the elements, but an appropriate grasp of meaningful overall institutions."[4] The ingenious arrangement and use of these visual elements creates different visual effects of different movie posters. These visual symbol elements seem ordinary, but each one or more of them combined effectively promotes the transmission of information, and different combinations bring different emotional experiences to the audience. The refinement and structure of symbols determine the pattern and design quality of movie posters.

Movie posters construct meaning through basic symbolic language, such as text symbols, graphic symbols and color symbols, and clearly convey the theme and content of the movie to the audience. ${ }^{[5]}$ Text symbols play a key role in conveying film information including descriptive information such as film name, slogan, director information, actor information and release time while graphic symbols mainly express portraits, character modeling, natural scenery etc. through visual perception. It mainly uses visual perception to explain the theme of the movie and quickly convey the information of the movie.

\section{Chinese And Foreign Movie Poster Design}

\subsection{Overview Of Foreign Movie Poster Design}

Since the first movie poster in the world "Train Arrival" was born in the 19th century, movie poster design has been studied and explored abroad. As the development of the times, the integration of new aesthetic ideas and the rise of design movements made the western movie poster design led by developed film systems such as Hollywood gradually found its own way.

Take the United States as an example, from the 1950s to the 1970s, the format of the movie posters back then was graphic instruction text. The linchpin graphics of the poster can be portraits, scenes or key props. The goal of the poster was to express the theme of the movie while attracting audience consumption in the theater. During this period, posters mostly appeared in hand-drawn form, while photos were more blank. Under the influence of the New York Institute of Graphic Design, they revealed a simple and rational style which is focusing on visual function and picture balance. ${ }^{[6]}$

Since the postmodernism of the late 1970s, the poster picture has become more informative, while new technology dividend becoming more maturer which was bought by the third industrial revolution, the poster can carry a better message, which makes the commercial value of the poster has been once again enhanced.

After entering the new century, movie posters have become the dominant portrait painting. Through a single poster, the audience can understand the roles and weights of different actors in the movie. At the same time, from the perspective of color usage, the film posters of this period are no longer tied to a large proportion of low-bright colors, but according to the style of the film itself to choose consistent colors. On the composition, the frame composition basically no longer appears, the composition form turned into diversified, the design is more and more inclusive. By summarizing the symbols of its movie posters, we can find the regular symbols in them.

For example, a poster with a back shadow symbol as Figure 1 shows is usually a typical Individual Heroic Films, which refers to the protagonist or protagonist group saves the world or fights against evil forces. In the design of movie posters, the main symbol is the central character of the movie. As far as the shape is concerned, choose clothes that correspond to the content of the movie to make the form looks like forward or backward slightly, by this way the poster can implant the image of the main character into the audience's consciousness easily. The composition is basically made by a simple movie scene with a big figure in the center.

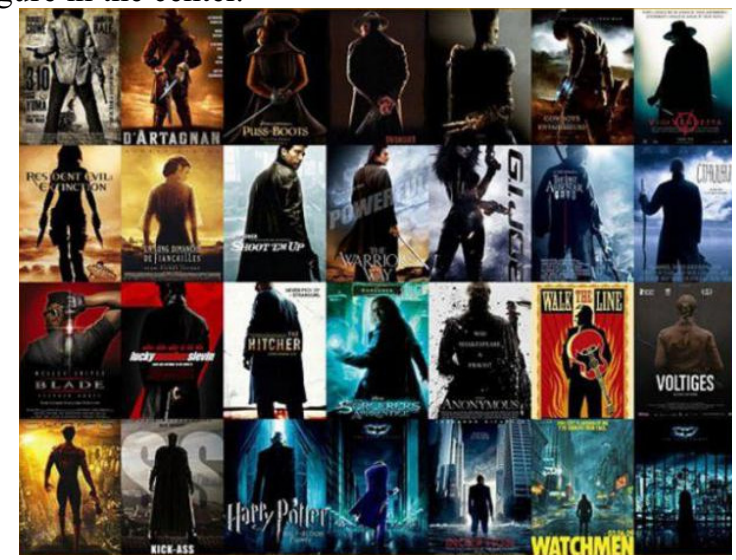

Figure 1: An overview of posters with back shadow symbols

Take another example as the movies with women as the protagonist, the female symbols in the posters can be basically divided into two categories according to the content. One type of female symbols is symbolized by the items with obvious feminine tendencies, such as high heels or lipsticks. These posters are mostly romantic comedies. Their main character of the movie often shows up as a classic charming woman, whose subject is to express the female's emotion and social experience. The other category of female symbols is a red-lip-based poster that basically tells the story of dangerous, provocative, stimulating, non-traditional women and combines it with spiritual or scary elements. 


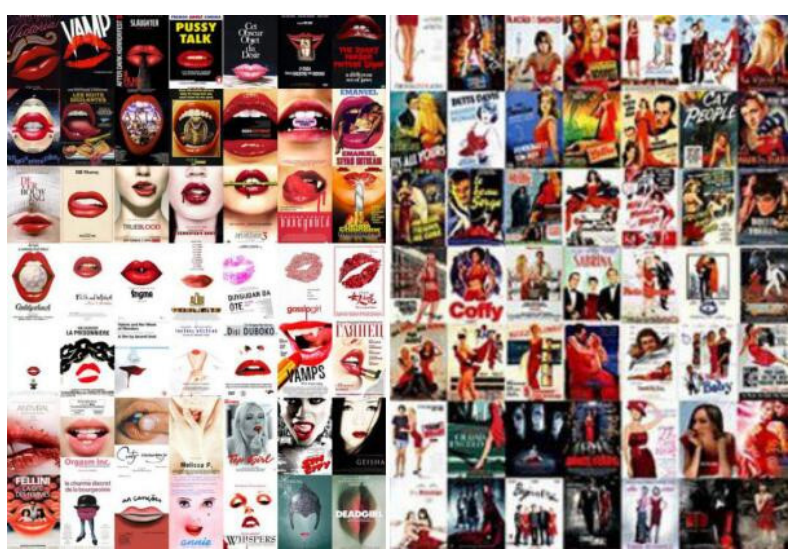

Figure 2: An overview of female symbol posters

\subsection{Overview Of Chinese Film Poster Design}

Compared with the booming foreign film industry, the Chinese film industry has been in a downturn. Not to mentioned domestic movie poster design has been a mechanical imitation of foreign poster design for a long time.

With the comprehensive reform and opening up of China's economy and society, many new design ideas and aesthetic theories have been continuously integrated into the Chinese market. Meanwhile the deepening of semiotic theory research has gradually transformed the form of movie posters from a single product into a diversified and thoughtful aesthetic artwork. The design of Chinese movie posters and movie posters is not only bringing more economic benefits to its affiliated movie industry, but also forming its own aesthetic and commercial value.

From the beginning of the founding of New China to before the reform and opening up, China's domestic film market was affected by the domestic political environment at that time and showed a strong political atmosphere. The creation basically follows the principle "revolutionary theme first", and its subject matter is basically to depict revolutionary heroes telling revolutionary stories through realistic means, and the film presents heroism and patriotism.

After the reform and opening up, the domestic film industry has ushered in a new development opportunity. Excellent foreign films are continually imported into the country. All kinds of new themes, new shooting techniques, and performance techniques are constantly present in the eyes of the Chinese people. The film market has more requirements for the quality of films. The themes of the film have also changed from a politically based film to a diversified development of social themes such as focusing on social culture and thinking about human nature. The design of movie posters has emerged with a variety of artistic expressions, so that the posters convey not only the content of the movie, but also the emotions of the characters in the movie. ${ }^{[7]}$

Especially since the beginning of the new century, the rapid development of new industrial technology in China has technically lifted the shackles that restricted the development of China's movie poster design, and poster design with Chinese characteristics has gradually sprouted.

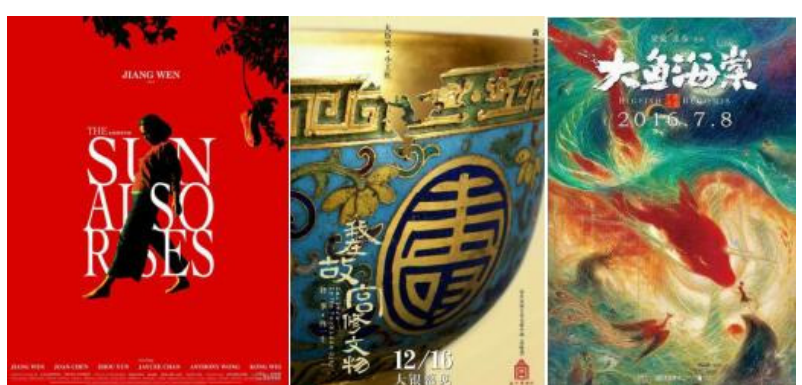

Figure 3: Modern Chinese posters

\section{Digital Symbols In Movie Poster Design}

Through further analysis of Chinese and foreign movie posters, the author also noticed the differences in the selection of symbols in the design of Chinese and foreign movie posters. In terms of symbolic meaning, it represents the actual meaning behind its form, so it will inevitably be affected by different regions, different beliefs, and different cultures. Therefore, there are situations where the same symbol expresses different meanings, or the same meaning is expressed by different symbols.

As one of the powerful media of cultural output, the movie itself can also be understood as a symbolic expression of the ideology it represents. In this sense, the movie poster is the further symbolization of the movie symbol. It can be found that the difference in visual graphic symbols is actually a cultural difference.

If we compare the ancient Greek civilization that represents the origin of Western civilization with the traditional Chinese civilization, we can find that Western civilization originated from marine civilization, based on commercial development, and cognitively externalized epistemological philosophy, emphasizing humanity and transformation, civilization first is religion that is the gods that embody all the wisdom and beauty of mankind are the highest, and they advocate democracy and the legal system, while Eastern civilization originated in the inland, farming led the development, cognitively internalized metaphysics, focusing on nature and obedience, civilization first is ethics that are moral virtue, the indescribable heaven is the highest, and they are advocating autocracy and family.

This difference in cultural development has caused obvious differences in the choice of symbols between the East and the West. According to this difference, symbols can be divided into Strong Western Symbols, Strong Eastern Symbols, and Weak Cultural Symbols. Strong Western Symbols include snakes, eyes, angels and demons, magic, crosses, scales, etc., while common Strong Eastern Symbols include ink painting, Tai Chi, martial arts and martial arts, square characters, tea, Westward Journey, etc.

Strong Western Symbols take the eye symbol as an example. From the eye of Horus on the ancient Egyptian murals to the eye of the omniscient and almighty God printed on the US dollar, the worship of the eye symbol in the Western world has never stopped, and China currently knows Only Sanxingdui showed worship for eyes in the culture. Therefore, Western posters dominated by eye 
symbols are mostly science fiction films or horror thrillers. Based on the expansion of the eyes and the application of auxiliary symbols such as bugs, roads, and flames, the tone of the film can be further speculated.

In terms of design techniques, this is the processing of the pupil, which is the central point of vision, by breaking the inertial thinking that has long been worshiped by the eyes to create a weird and supernatural visual effect, and arouse the audience's curiosity.

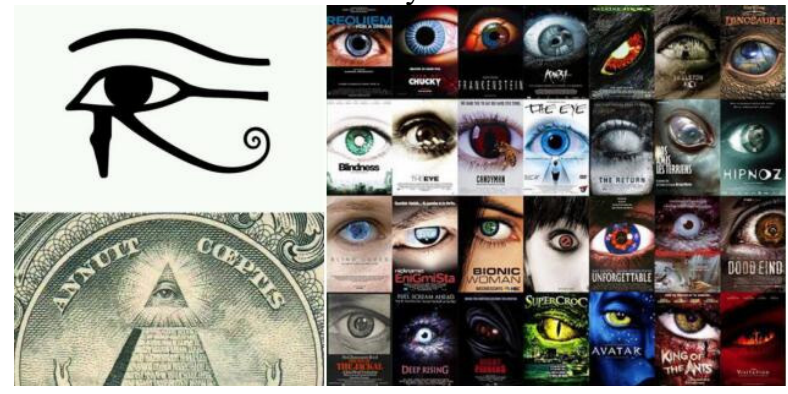

Figure 4: Posters related to eye symbols

The Strong Oriental Symbol takes the ink symbol as an example. Designers often use the uncertainty of ink flow to create a wanton and arrogant film's tone. Therefore, it is often combined with martial arts movies or rendered the background era of the movie with the unique effect of ink and wash. As a traditional calligraphy and painting technique for a long time, ink and wash symbols are well integrated with Chinese calligraphy culture, making the font design of Chinese movie posters have unique advantages. At the same time, the black and white parts of the screen divided by ink and wash are highly integrated with Taoist culture's Tai Chi and Yin Yang doctrine. Therefore, movies with ink and wash elements often tell stories of traditional China rather than modern China, and their core content is mostly related to traditional culture.

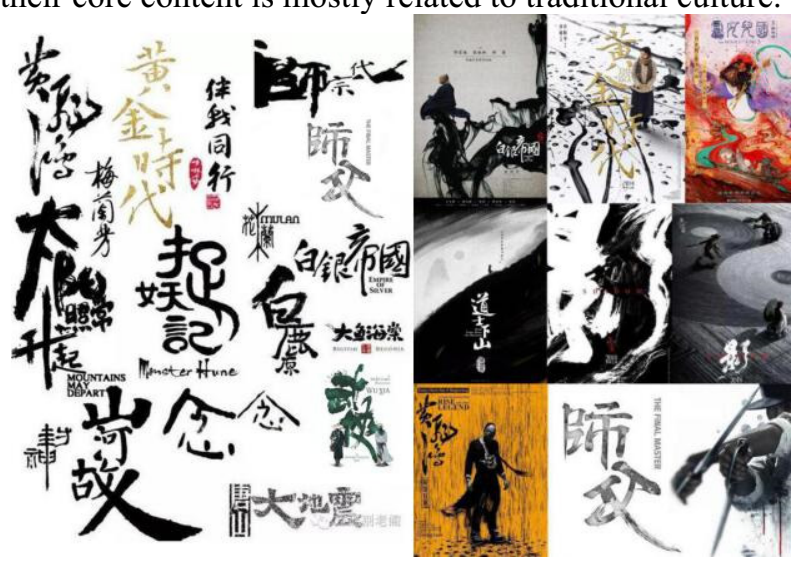

Figure 5: Posters related to ink and wash symbols

Weak Cultural Symbols take firearms as an example. Since automatic firearms have been widely used after the 19th century, in the cultures of countries around the world who have been through twice World Wars, firearms have represented violence and blood, and then developed into law enforcement and conflict. Synonymous, movie posters with gun-related symbols such as bullets, sights, etc. usually have elements such as action, gangsters, war, and police. This type of film uses a combination of violence-related symbols to stimulate the audience's adrenaline in order to satisfy the desire of audience to make them watching movies.

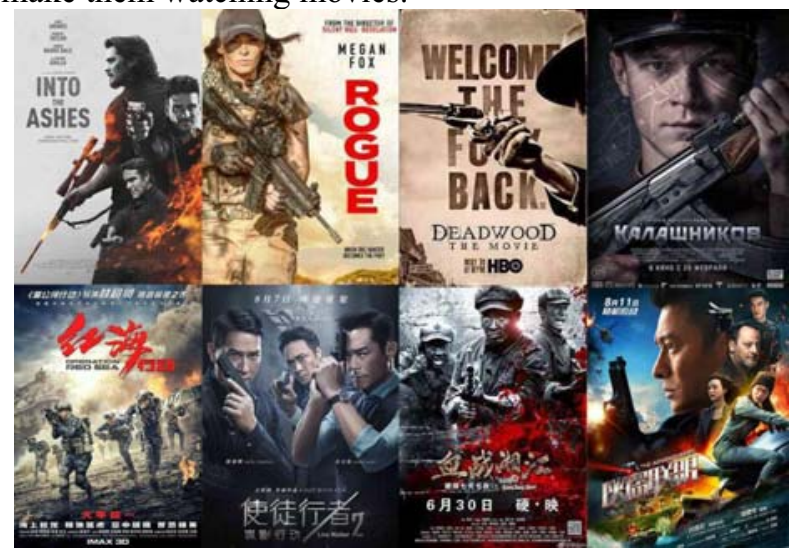

Figure 6: Posters related to firearms symbols

From the analysis above, it can be found that excellent poster design often follow their own culture in the choice of symbols, and find elements that fit the film from the local culture. Take "Alien" posters and "The Golden Era" posters as examples.

In the "Alien" poster, the poster is expressed in relief, and at the same time, with the help of the twisted and struggling image of the ancient Greek statue "Laocoon", it expresses the cruel struggle between humans and aliens, and gives it a civilized epic sense.

In "The Golden Era", the text is decomposed into scattered and messy strokes, and the straight and oblique strokes form an illusory wall, and different characters shuttle in the "virtual" space. ${ }^{[8]}$ These graphic symbols formed by the strokes give people a strong sense of sharpness and oppression, which is in sharp contrast with the little characters on the posters, which means the turbulent era and the protagonist's life.

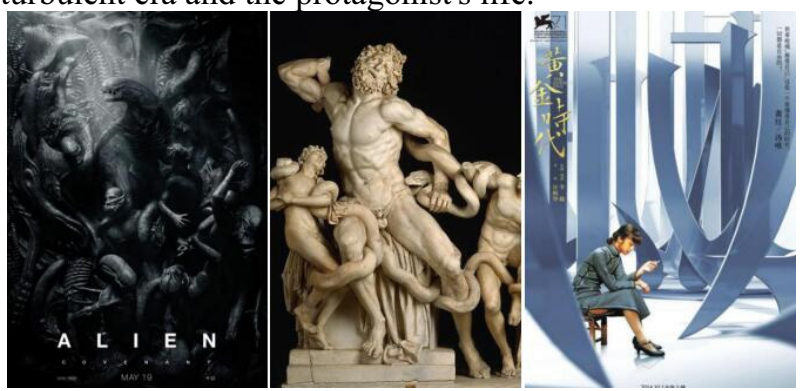

Figure 7: Poster of "Alien" and "The Golden Era"

\section{Summary}

This article briefly describes the development of movie posters at home and abroad, and discusses the use of cultural symbols in the design of movie posters in different cultural backgrounds from the perspective of cultural symbol digitization. The author believes that the movie poster is the symbolic symbol of the story of the movie, and the visual expressiveness of its "signifier" is the most easily received visual symbol by the audience. Only when the, poster is attracted, the audience is willing to watch the movie.

Therefore, the design of Chinese movie posters needs 
to extract more Chinese-style symbols with Chinese flavor of the local culture, and output Chinese culture and values to the world through digital design of these symbols.

\section{REFERENCES}

1. Hu Yirong. Image Semiotics: Schematic Grasping of the Media Landscape World [M]. Chengdu: Sichuan University Press, 2014: 6

2. Lv Jiabei. Semiotics and product semantics in movie posters[J]. Art Education Research, 2018(08): 37.

3. Wang Ting. Visual Rhetoric: Viewing the Construction of National Image from the "Seventeen Years" Movie Posters[J]. Film Criticism, 2020(01): 49-53.

4. Li Henan. Research on Visual Symbols and Audience Cognition of Chinese Movie Posters [D]. Hunan Normal University, 2018.

5. Zeng Ying. Analysis of Huanghai Movie Poster Design from the Perspective of Symbols[J]. Art Theory, 2018(01):174-177.

6. Gao Mengyao. Analysis of the visual symbols in the design of American movie posters[J]. Art Research Express, 2020(1):1-5.

7. Hong Xiaonan, Li Xinyi. The style evolution and development of new China movie poster designTaking the works of the New China classic movie poster exhibition of Jilin University of the Arts as an example [J]. Journal of Jilin University of the Arts, 2019(05): 19-22.

8. Ren Hongli. Exploring the aesthetic meaning of "Golden Age" movie posters[J]. Sichuan Drama, 2016(10):140-142 